Mariana Nascimento Barbosa Lins ${ }^{\mathrm{a}}$ (iD) https://orcid.org/0000-0003-2966-0179

Luiz Marcello de Almeida Pereirab (iD) https://orcid.org/0000-0002-4778-0556

Maria Lúcia Vaz Masson

(D) https://orcid.org/0000-0003-0733-1753

a Universidade Federal da Bahia,

Instituto de Ciências da Saúde,

Departamento de Fonoaudiologia.

Salvador, Bahia, Brasil.

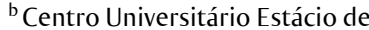
Sá/Bahia. Salvador, Bahia, Brasil.

Contato:

Maria Lúcia Vaz Masson

E-mail:

masson@ufba.br

Os autores informam que o estudo recebeu apoio por meio de bolsa de iniciação científica PIBIC/CNPq (Processo no 123154/2016-2).

Os autores declaram que não há conflitos de interesses.

Os autores informam que este artigo é baseado no Trabalho de Conclusão de Curso de Graduação em Fonoaudiologia intitulado "Danos morais por distúrbio de voz relacionado ao trabalho: levantamento de julgados do Tribunal Superior do Trabalho", de Mariana Nascimento Barbosa Lins, apresentado em 2017 na Universidade Federal da Bahia.

Os autores informam que este trabalho foi apresentado nos eventos científicos: a) Congresso de Pesquisa, Ensino e Extensão da Universidade Federal da Bahia (Salvador, BA, 2017), título: O distúrbio de voz relacionado ao trabalho nas decisões do Tribunal Superior do Trabalho; b) XXV Congresso Brasileiro de Fonoaudiologia (Salvador, BA, 2017), título: O distúrbio de voz relacionado ao trabalho nas decisões do Tribunal Superior do Trabalho. Ambos com resumo publicado nos anais.

\section{Danos morais por distúrbio de voz relacionado ao trabalho: levantamento de julgados do Tribunal Superior do Trabalho}

\author{
Moral damages due to work-related voice disorder: \\ the Brazilian Superior Labor Court judgments
}

\section{Resumo}

Introdução: trabalhadores expostos a condições ocupacionais inadequadas podem ser acometidos por distúrbio de voz relacionado ao trabalho (DVRT). Enquanto o DVRT não é legalmente reconhecido, há uma fragilização no estabelecimento do nexo causal entre trabalho e agravo vocal. Objetivo: analisar as decisões do Tribunal Superior do Trabalho (TST) nas ações movidas por trabalhadores que alegaram DVRT na Justiça. Método: estudo quantitativo, exploratório e descritivo. Para o levantamento dos acórdãos, utilizou-se o termo de busca "disfonia" no portal do TST. Resultados: identificaram-se 87 acórdãos proferidos entre os anos de 1999 a 2016, impetrados sobretudo por mulheres $(88,5 \%)$, do setor de Teleatendimento (59,8\%). Em 39,1\% das ações, houve reconhecimento do nexo causal entre o trabalho e a doença, ganho de causa parcial $(42,5 \%)$, indenização por danos morais $(50,6 \%)$, indenização por danos materiais $(8,0 \%)$, e multa $(5,7 \%)$. Conclusão: os acórdãos mostraram a relação entre distúrbio de voz e trabalho. O reconhecimento legal do DVRT poderá contribuir para a redução do sofrimento e do tempo de espera do trabalhador pela compensação por seu adoecimento. Também poderá auxiliar na construção de políticas públicas que visem a promoção, proteção, recuperação e, sobretudo, vigilância em saúde, de modo a garantir condições de trabalho adequadas para o uso da voz no trabalho.

Palavras-chave: legislação; trabalho; distúrbios de voz; saúde do trabalhador.

\begin{abstract}
Introduction: workers exposed to inadequate occupational conditions may be affected by work-related voice disorder (WRVD). While WRVD is not legally acknowledged, there is a weak causal association between work and voice disorders. Objective: to analyze the decisions of the Brazilian Superior Labor Court (TST) regarding actions taken by workers claiming WRVD. Method: quantitative, exploratory and descriptive study. We searched for the term "disfonia" (dysphonia) in the TST database. Results: 87 judgment records were identified between 1999 and 2016, requested mainly by women (88.5\%); the most frequent sector was telemarketing (59.8\%). In $39.1 \%$ of the actions, the causal association between work and the disease was acknowledged determining partial compensation (42.5\%), compensation for moral damages (50.6\%), compensation for material damage (8.0\%) and fines (5.7\%). Conclusion: the court judgments established the relationship between voice disorder and work. WRVD legal acknowledgment may contribute to the reduction of the workers' suffering and waiting time for their compensation claims. It can also help to develop public policies focused on the promotion, protection, recovery and, mainly, health surveillance, in order to ensure adequate working conditions for the use of voice at work.
\end{abstract}

Keywords: legislation; work; voice disorders; occupational health. 


\section{Introdução}

A doença ocupacional é caracterizada como o adoecimento no exercício profissional, que tem o trabalho como determinante. De acordo com a Lei $\mathrm{n}^{\circ} 8.213 / 91$, as doenças ocupacionais têm o mesmo regime do acidente de trabalho ${ }^{1}$. Desse modo, os trabalhadores, uma vez adoecidos em sua atividade profissional, teriam a possibilidade de buscar benefícios compensatórios no âmbito da Previdência Social e direitos decorrentes da relação de emprego na Justiça do Trabalho.

Para uma doença ser considerada ocupacional, é necessário haver o nexo entre agravo e trabalho ${ }^{2}$, constituindo-se requisito para o benefício previdenciário (após o $15^{\circ}$ dia de afastamento), para a estabilidade no emprego e para a continuidade dos depósitos no Fundo de Garantia pelo Tempo de Serviço (FGTS) ${ }^{3}$. Esse nexo pode ser presumido ou comprovado por exame clínico, realizado pelo médico da empresa ou por peritos do Instituto Nacional do Seguro Social (INSS) ${ }^{2}$.

O Regulamento da Previdência (Decreto $\mathrm{n}^{\circ}$ $3.048 / 99)^{3}$, na redação dada pelo Decreto $n^{0} 6.957 / 09^{4}$, traz as listas "A", "B" e "C" em seu anexo II. A lista "C" indica os agravos, segundo a Classificação Estatística Internacional de Doenças e Problemas Relacionados com a Saúde, $10^{\mathrm{a}}$ Edição (CID-10), e a atividade profissional, pela Classificação Nacional de Atividades Econômicas (CNAE), nos quais se reconhece nexo técnico epidemiológico entre a entidade mórbida e as classes da $\mathrm{CNAE}^{5}$. Se o agravo e a atividade profissional estiverem relacionados nessa lista, o nexo se presume, tornando-se desnecessário o exame de cada caso individual para comprovação clínica.

O distúrbio de voz relacionado ao trabalho (DVRT) é definido como um desvio vocal observado ao longo do trabalho, referente à ocupação exercida, que pode impedir ou comprometer o exercício profissional do trabalhador ${ }^{6}$. Não há referência geral ao DVRT ${ }^{2,4}$ nas listas do Anexo II do Regimento da Previdência. Assim, a compensação por seus danos ao trabalhador depende da prova da relação de causalidade entre o trabalho e o agravo vocal, realizada caso a caso. Também, ressalta-se que há legislação específica somente sobre o Teleatendimento, regulamentada pelo Anexo II $^{7}$ da Norma Regulamentadora 17 (NR-17) $^{8}$, editada pelo extinto Ministério do Trabalho e Emprego (MTE), porém não se estabelece a presunção do nexo nessa norma.

As categorias profissionais mais acometidas por DVRT são a dos professores e a dos teleoperadores. Segundo Martins et al. ${ }^{9}$, professores possuem maior prevalência de distúrbios vocais em comparação a outras categorias, chegando a $80 \%$ de prevalência em docentes. Em seguida, encontram-se os teleoperadores com prevalência de $33 \%$ de distúrbios vocais ${ }^{10}$. Sabe-se que o número de trabalhadores que utiliza a voz como principal recurso em suas atividades de trabalho aumentou significativamente nas últimas décadas, especialmente, na área do Telesserviço, contabilizando 1,4 milhão de postos de trabalho na atividade de Teleatendimento em todo o território nacional ${ }^{11}$. Dados da Associação Brasileira de Telemarketing (ABT) revelam crescimento de $198 \%$ depois da privatização dos serviços de telefonia, com crescimento de $11 \%$ ao ano $^{12}$. Quanto aos docentes, segundo dados de 2017 do Instituto Nacional de Estudos e Pesquisas Educacionais Anísio Teixeira (Inep), somente na Educação Básica do Brasil, somam-se 2,2 milhões de professores ${ }^{13}$. Considerando-se as condições de trabalho e os fatores de risco aos quais os profissionais estão expostos, tal crescimento pode também revelar aumento na incidência de problemas de voz nessas principais categorias.

Para uso clínico e epidemiológico, o Ministério da Saúde (MS) emitiu a Portaria GM/MS no 1339/99, "lista-mãe" 14 , que relaciona adoecimento a fatores de risco de ordem ocupacional. A lista abrange aproximadamente duzentas entidades nosológicas, elencadas respectivamente pela CID-10. Esses agravos foram descritos no Manual de Procedimentos de Doenças Relacionadas ao Trabalho ${ }^{15}$ com o objetivo de orientar os profissionais de saúde para prevenção, vigilância e assistência à saúde dos trabalhadores. Não foi incluído, nessa lista, o distúrbio de voz. Somente em 2018, o MS publicou o Protocolo DVRT $^{6}$, que tem por finalidade direcionar os profissionais da saúde da rede do Sistema Único de Saúde (SUS) e dos serviços privados para a identificação, a notificação e o subsídio das ações de vigilância dos casos de DVRT e de seus determinantes ${ }^{6}$. Na atualização da lista das doenças relacionadas ao trabalho (LDRT), recentemente publicada por meio da Portaria GM/MS n ${ }^{0}$ 2.309/20 $0^{16}$ em 28 de agosto de 2020, o distúrbio de voz foi incluído dentre os agravos, sendo o "trabalho com sobrecarga vocal" o principal fator/agente de risco, com aspectos agravantes ligados a "fatores psicossociais relacionados à característica e organização do trabalho" e "fatores relacionados ao ambiente de trabalho". Constitui-se por 347 doenças, a maioria de natureza infecciosa/ parasitária (incluindo a COVID-19) e neoplasias. A ocupação/ramo de atividade econômica deixaram de ser considerados, por não estarem presentes em todos os agravos/doenças na versão anterior, além de limitar a relação com o trabalho em determinadas ocupações. A referida normativa foi revogada um dia após sua publicação no Diário Oficial da União (DOU), por meio da Portaria GM/MS n ${ }^{\circ} 2.345 / 20^{17}$. Mesmo que ainda estivesse válida, não se presumiria o nexo causal, que é do âmbito previdenciário, uma vez que expressa finalidade clínico-epidemiológica, 
de atenção integral à Saúde do Trabalhador, de modo a orientar ações de vigilância e promoção da saúde em nível individual e coletivo ${ }^{16}$.

De acordo com o Protocolo DVRT ${ }^{6}$, os fatores de risco estão relacionados à organização e ao ambiente de trabalho como também fatores ligados ao indivíduo. Ao que concerne à organização do trabalho, consideram-se riscos: sobrecarga de atividades; longa jornada de trabalho; uso excessivo da voz; inexistência de intervalos e locais para repouso; falta de autonomia; prioridade no cumprimento de metas, gerando sobrecarga na jornada de trabalho; descontentamento com a remuneração ou trabalho realizado; postura e aparatos inapropriados; acesso inadequado aos sanitários e pouca hidratação.

Os principais riscos ambientais relacionados ao local de trabalho se constituem em: intensidade sonora acima dos níveis de conforto; acústica inadequada; recursos materiais restritos ou inapropriados; qualidade e umidade baixa do ar; ventilação inadequada do ambiente; desconforto e choque térmico; fumaça ou poeira no ambiente de trabalho e exposição a produtos químicos prejudiciais às vias aéreas superiores ${ }^{6}$.

Quanto aos aspectos relacionados ao indivíduo, são ressaltados: faixa etária; sexo; patologias que abrangem as vias aéreas superiores; alergias respiratórias; consumo de álcool e tabaco; medicações e questões hormonais ${ }^{6}$.

Na nova LDRT, então revogada, apresentava-se o fator

trabalho com sobrecarga vocal associada e/ou agravada por:

a) fatores psicossociais relacionados à característica e organização do trabalho: jornada de trabalho prolongada, sobrecarga, acúmulo de atividades ou de funções, ausência de pausas e de locais de descanso durante a jornada, falta de autonomia, ritmo de trabalho acelerado para o cumprimento de metas, trabalho sob forte pressão, insatisfação com o trabalho ou com a remuneração, postura e equipamentos inadequados, dificuldade de acesso à hidratação e aos sanitários, dentre outros não especificados;

b) fatores relacionados ao ambiente de trabalho: pressão sonora acima dos níveis de conforto, acústica desfavorável, mobiliário e recursos materiais inadequados ou insuficientes, desconforto e choque térmico, má qualidade do ar, ventilação inadequada do ambiente, baixa umidade, exposição a produtos químicos irritativos de vias aéreas superiores (solventes, vapores metálicos, gases asfixiantes) e presença de poeira ou fumaça no local de trabalho, dentre outros não especificados. (p. 57) ${ }^{16}$

A falta de condições satisfatórias do ambiente e da organização do trabalho para o exercício profissional gera o risco de adoecimento. A ausência de legislação que acolha os trabalhadores adoecidos no âmbito da Previdência os impele a procurar na Justiça o reparo aos danos sofridos. Este artigo tem por objetivo analisar as decisões do Tribunal Superior do Trabalho (TST) em ações movidas por trabalhadores que iniciaram processo judicial alegando DVRT.

\section{Método}

Pesquisa quantitativa, exploratória e descritiva sobre trabalhadores que recorreram à Justiça para reparação aos danos causados à sua voz no exercício da profissão. Utilizou-se como unidade de análise os acórdãos, documentos com a resolução ou decisão final de uma ação tomada coletivamente pelos tribunais ${ }^{18}$, proferidos pelos ministros do TST.

Os documentos foram coletados no período de outubro de 2016 a junho de 2017. O corpus selecionado foi constituído pela totalidade dos acórdãos disponíveis no portal "Pesquisa em Jurisprudência" do TST (https://jurisprudencia.tst.jus.br/) ${ }^{19}$, de acesso aberto ao público. Empregou-se, a palavra-chave "disfonia" como termo de busca, sendo incluída a totalidade de acórdãos encontrados para este estudo.

Realizou-se, incialmente, análise exploratória dos acórdãos, levando-se em consideração as informações disponíveis nos documentos. A partir da leitura e análise de inteiro teor dos acórdãos, definiram-se as variáveis para esta pesquisa: sexo, profissão, ramo de atividade, pedido do trabalhador junto ao Judiciário, ano de início e fim do processo, caracterização do distúrbio de voz pelo juiz, nexo causal e tipos de ganho (concessão de benefício previdenciário, ganho de causa por danos morais, danos materiais e multa). A idade dos requerentes, embora prevista como uma possível variável, não foi considerada pelo fato de não haver essa informação nos acórdãos.

As variáveis foram organizadas em banco de dados especificamente elaborado para este estudo, apresentado em planilha do programa Microsoft Excel (versão 2016), descritas em termos de frequência para variáveis categóricas; média, mínima e máxima, para as variáveis contínuas e analisadas por meio do programa Statistical Package for the Social Sciences (SPSS) para Windows, versão 20.0.

Este estudo é parte de um projeto maior, que busca evidências para o reconhecimento do distúrbio de voz como doença relacionada ao trabalho, aprovado pelo Comitê de Ética em Pesquisa do Instituto de Ciências da Saúde, da Universidade Federal da Bahia, sob o parecer $n^{0} 1.899 .690$, de 28/01/2017. 


\section{Resultados}

Foram encontrados 99 acórdãos no portal do TST. Após varredura prévia, observou-se que cinco deles se repetiam (tratava-se dos mesmos casos, porém em uma etapa mais avançada do processo), permanecendo 94 documentos. Destes, apenas 87 estavam relacionados ao DVRT, sendo considerados para análise. O ano de início das ações variou entre 1999 e 2014, com término entre 2003 e 2016.
Na Tabela 1 encontram-se descritas profissões, sexo e ramos de atividades dos trabalhadores envolvidos nas ações judiciais, como também a delimitação do pedido desses profissionais, inferidos a partir dos acórdãos.

Na Tabela 2 são elencadas as condições em que os trabalhadores se encontravam no momento em que a ação foi impetrada, levando-se em conta tipo de distúrbio vocal e o reconhecimento da existência do nexo causal entre doença e trabalho. A Tabela 3 apresenta a conclusão da ação segundo a análise do Judiciário.

Tabela 1 Caracterização do gênero, profissão, ramo de atividade e pedido do trabalhador em ações envolvendo distúrbios de voz relacionados ao trabalho, presentes em acórdãos do Tribunal Superior do Trabalho no período de 1999 a 2016

\begin{tabular}{|c|c|c|}
\hline Variáveis & $n$ & $\%$ \\
\hline \multicolumn{3}{|l|}{ Gênero } \\
\hline Feminino & 77 & 88,5 \\
\hline Masculino & 10 & 11,5 \\
\hline \multicolumn{3}{|l|}{ Profissão } \\
\hline Teleoperador & 52 & 59,8 \\
\hline Professor & 18 & 20,7 \\
\hline Não Informado & 11 & 12,6 \\
\hline Auxiliar Administrativo & 2 & 2,3 \\
\hline Auxiliar de Limpeza & 1 & 1,1 \\
\hline Diretor Comercial & 1 & 1,1 \\
\hline Palestrante & 1 & 1,1 \\
\hline Preparador de Peças & 1 & 1,1 \\
\hline \multicolumn{3}{|l|}{ Ramo de atividade } \\
\hline Teleatendimento & 52 & 59,8 \\
\hline Educação & 19 & 21,8 \\
\hline Não informado & 11 & 12,6 \\
\hline Atividades auxiliares & 3 & 3,4 \\
\hline Comércio & 1 & 1,1 \\
\hline Fabricação & 1 & 1,1 \\
\hline \multicolumn{3}{|l|}{ Pedido do trabalhador } \\
\hline Indenização por dano moral e outros & 71 & 81,6 \\
\hline Nulidade de dispensa e outros & 6 & 6,7 \\
\hline Provisória e outros & 3 & 3,3 \\
\hline Honorários advocatícios e outros & 3 & 3,3 \\
\hline Negativa de prestação jurisdicional & 1 & 1,1 \\
\hline Nulidade de decisão & 1 & 1,1 \\
\hline Indenização por dano material e outros & 1 & 1,1 \\
\hline Intervalo Intrajornada & 1 & 1,1 \\
\hline
\end{tabular}

Indenização por dano moral e outros: indenização à vítima pelo tratamento indigno a ela dispensado ou pela dor psíquica causada pela conduta do empregador; Nulidade de dispensa e outros: o Judiciário anula a dispensa do empregado, com consequente reintegração; Provisória e outros: decisão tomada de forma que pode ser modificada ou anulada em razão provisória da pendência de um recurso interposto contra ela; Honorários advocatícios e outros: remuneração que a parte vencida em pleito judicial é condenada a pagar ao advogado da parte contrária; Negativa de prestação jurisdicional: pronunciamento do Judiciário necessário para que algum dado apresentado por defesa ou acusação seja examinado; Nulidade de decisão: decisão judicial nula; Indenização por dano material e outros: indenizar o trabalhador pelo valor em dinheiro que ele deixará de ganhar em decorrência do DVRT; Intervalo Intrajornada: concedido durante a jornada de trabalho. 
Tabela 2 Distúrbio de voz descrito no acórdão e nexo entre doença/trabalho, segundo a análise do juiz, presentes em acórdãos do Tribunal Superior do Trabalho no período de 1999 a 2016

\begin{tabular}{lcc}
\hline Variáveis & $n$ & $\%$ \\
\hline Tipo de Distúrbio Vocal & 60 & 69,0 \\
Disfonia & 8 & 9,2 \\
Disfonia Funcional & 4 & 4,6 \\
Disfonia Organofuncional & 3 & 3,4 \\
Doença Crônica & 3 & 3,4 \\
Patologia & 2 & 2,3 \\
Disfonia Psicogênica & 1 & 1,1 \\
Afonia & 1 & 1,1 \\
Alteração de Voz & 1 & 1,1 \\
Disfonia Orgânica & 1 & 1,1 \\
Disfonia Organofuncional/Disfonia Funcional & 1 & 1,1 \\
Disfunção no aparelho fonador & 1 & 1,1 \\
Fadiga e desgaste vocal & 1 & 1,1 \\
Nódulo & & \\
Nexo entre doença e trabalho & 23 & 26,4 \\
Ausência de nexo causal & 4 & 4,6 \\
Inconclusivo & 26 & 29,9 \\
Não Informado & 34 & 39,1 \\
Confirmação de nexo causal & & \\
\hline
\end{tabular}

Tipo de Distúrbio Vocal: denominação dada às alterações vocais pelos Juízes

Tabela 3 Resultado das ações envolvendo distúrbios de voz relacionados ao trabalho presentes em acórdãos do Tribunal Superior do Trabalho no período de 1999 a 2016

\begin{tabular}{|c|c|c|c|}
\hline Variáveis & n & $\%$ & $\begin{array}{l}\text { Resultado da ação } \\
\text { Valor médio- } R \$ \\
\text { (mínimo-máxima) }\end{array}$ \\
\hline \multicolumn{4}{|l|}{ Ganho de causa } \\
\hline Inconclusivo & 2 & 2,3 & \\
\hline Parcial & 37 & 42,5 & \\
\hline Integral & 27 & 31,0 & \\
\hline Perda & 21 & 24,1 & \\
\hline \multicolumn{4}{|l|}{ Benefício } \\
\hline Não & 60 & 69,0 & \\
\hline Sim & 27 & 31,0 & \\
\hline \multicolumn{4}{|c|}{ Indenização por Danos Morais } \\
\hline Inconclusivo & 1 & 1,1 & \\
\hline Não & 42 & 48,3 & \\
\hline Sim & 44 & 50,6 & $\begin{array}{c}14.627,08 \\
(4.000,00-60.000,00)\end{array}$ \\
\hline \multicolumn{4}{|c|}{ Indenização por Danos Materiais } \\
\hline Inconclusivo & 1 & 1,1 & \\
\hline Não & 79 & 90,8 & \\
\hline Sim & 7 & 8,0 & $\begin{array}{c}8.250,00 \\
(1.500,00-20.000,00)\end{array}$ \\
\hline \multicolumn{4}{|l|}{ Multa } \\
\hline Não & 82 & 94,3 & \\
\hline Sim & 5 & 5,7 & $\begin{array}{c}750,00 \\
(500,00-1.000,00)\end{array}$ \\
\hline
\end{tabular}




\section{Discussão}

Os resultados demonstraram um longo período para a conclusão das ações movidas - 4 a 17 anos -, em sua maioria, movidas por profissionais do ramo de Telefonia (59,8\%), seguido pela Educação (21,8\%). Houve indenização por danos morais (50,6\%), ganho de causa parcial $(42,5 \%)$, reconhecimento do nexo causal entre trabalho e doença $(39,1 \%)$, multa ao empregador (5,7\%) e indenização por danos materiais $(8,0 \%)$. O ganho da causa é parcial quando o Poder Judiciário atende a uma parcela das solicitações realizadas pelo trabalhador no decorrer da decisão judicial.

Em relação à população, foram encontrados, em maior número, indivíduos do sexo feminino (88,5\%). Apesar das mulheres apresentarem, constitucionalmente, maior predisposição a alterações vocais, como é consenso na literatura ${ }^{6,20,21}$, seja por problemas hormonais, maior número de vibrações por segundo ou anatomia da laringe ${ }^{20}$, os fatores relacionados ao trabalho são decisivos para o adoecimento e, do ponto de vista jurídico, configura-se sob esses aspectos, a concausalidade $^{6}$. Segundo o conceito referido, o trabalho pode ser entendido como fator contributivo ou agravante de doença pré-existente ${ }^{5,22}$. Desse modo, independentemente da existência de um fator pessoal predisponente, o reconhecimento do nexo entre trabalho e agravo pode ser, factualmente, comprovado.

\section{Profissão}

A maioria dos trabalhadores que moveram ação judicial foi composta por profissionais da voz $(81,6 \%)$ : teleoperador $(59,8 \%)$, professor $(20,7 \%)$ e palestrante $(1,1 \%)$. As únicas exceções foram: auxiliar de limpeza $(1,1 \%)$ e preparador de peças $(1,1 \%)$. Quanto à categoria de auxiliar de limpeza, o Poder Judiciário decidiu pela ausência do nexo entre o trabalho e o agravo e destacou que, nessas ocupações, o trabalhador não utilizaria a voz como recurso principal para desenvolver suas atividades. O laudo otorrinolaringológico sugeriu disfonia psicogênica, restringindo a interpretação de um distúrbio de voz a um evento com marcas orgânicas. No caso do preparador de peças, o laudo otorrinolaringológico indicou "nódulos de corda vocal”. Devido ao "intenso ruído e calor excessivo" no ambiente de trabalho, o Judiciário encerrou a questão, reconhecendo o nexo de causalidade entre o agravo e o trabalho, pois "o trabalhador fazia uso constante da voz". Observa-se que, com a classificação mais recente de Costa et al. ${ }^{23}$, o primeiro caso teria a possibilidade de ser considerado como um DVRT, tendo em vista a exposição a fatores químicos, como produtos de limpeza. E no segundo caso, além da "fadiga vocal”, mencionada pelo Judiciário, relacionada ao uso constante da voz, seria um exemplo ilustrativo da categoria "problemas de voz relativos ao contato com substâncias irritativas" ${ }^{23}$, no qual o componente de exposição (produtos químicos mencionados no acórdão: ácido nítrico, hidrocarbonetos aromáticos, querosene, thinner, percloroetileno e óleo mineral) e o agravo estão presentes, independentemente do uso profissional da voz no trabalho.

Por atribuírem ao distúrbio de voz caráter biologizante, outras terminologias são empregadas para a definição do DVRT, como Síndrome Disfônica Ocupacional (SDO $)^{24}$ e Disfonia Ocupacional ${ }^{25}$. Nessa concepção, isolando-se os agentes etiológicos, os sintomas do agravo seriam eliminados e os profissionais da voz não ficariam incapacitados em relação à continuidade de suas atividades de trabalho, salvo se houvesse lesões de laringe, designadas como Laringopatia Ocupacional ${ }^{26}$. Essas terminologias foram encontradas nos acórdãos pesquisados, sendo observadas quando os peritos médicos se reportavam aos distúrbios vocais desenvolvidos pelos profissionais da voz. Muitas vezes, deixavam de considerar que, embora o trabalhador ainda não tivesse lesão aparente, poderia estar no processo do seu desenvolvimento, como uma disfonia funcional $^{20}$, uma vez que já se verificava alteração vocal devido ao trabalho.

Os problemas de voz, com base no comportamento vocal, abrangem as disfonias funcionais e organofuncionais ${ }^{20}$. A ausência dos cuidados básicos com a voz leva em consideração os comportamentos vocais alterados, que consistem em falar por longos períodos de tempo, aumentar a velocidade de fala, realizar ataques vocais bruscos, pigarrear, sussurrar, falar competindo com o ruído de fundo e usar continuamente qualidade vocal tensa e comprimida $^{20}$. O comportamento vocal alterado é fator central para o surgimento da disfonia funcional; contudo, sua etiologia é multifacetada e pode estar relacionada a questões de ordem psicológica e predisposições anatomofuncionais ${ }^{27}$.

Desvios no comportamento vocal, somados à inadequação da atividade muscular, podem resultar em lesões de massa benignas, a exemplo de pólipos e nódulos vocais, caracterizando as disfonias organofuncionais ${ }^{27}$. A falta de consenso em relação às terminologias que designam o DVRT é outro fator que dificulta o seu reconhecimento como doença relacionada ao trabalho ${ }^{5}$. Ações preventivas poderiam ser iniciadas, levando à interrupção do processo de adoecimento antes de uma piora no quadro, o que poderia impedir o desenvolvimento de uma lesão e, portanto, implicar em tratamento menos demorado e custoso. 


\section{Ramo de Atividade}

Os setores de Telesserviço (59,8\%) e de Educação $(20,7 \%)$ foram os mais frequentes neste estudo, refletindo as profissões com maior prevalência de DVRT. Pesquisas destacam que os professores e os teleoperadores são os profissionais da voz que mais apresentam distúrbios de voz, em comparação com a população geral ${ }^{9,10,28,29}$. Com este argumento, apresentaram-se projetos de lei com a finalidade de assegurar ações de prevenção da disfonia e promoção da saúde vocal, buscando reduzir as ocorrências de distúrbios de voz nesses profissionais. Apesar disso, grande parte desses projetos não foram, de fato, positivados em leis ${ }^{30}$.

Dentre as profissões relatadas nos acórdãos, o Telesserviço é o único setor com uma norma regulamentadora própria (NR-17) ${ }^{8}$, que define procedimentos a serem seguidos, relacionados tanto ao ambiente (ventilação, temperatura, umidade e ruído), quanto à organização do trabalho (autonomia, jornada de trabalho, demanda de produção, violência, local para descanso). Também, abarca aspectos relativos à saúde vocal e vigilância à saúde ${ }^{31}$.

Mesmo com a existência dessa norma específica ${ }^{2}$, referente à segurança e saúde dos teleoperadores, estes profissionais continuam, recorrentemente, adoecendo, mostrando-se como a profissão mais frequente em procura por reparação na Justiça do Trabalho. Ressaltam-se, também, equívocos ou ausência de base científica para muitas das definições estabelecidas na NR-178 . O item 8.2.1 da referida norma estabelece restritas medidas para promover a saúde vocal do teleoperador, a saber, “a) modelos de diálogos que favoreçam micropausas e evitem carga vocal intensiva do operador; b) redução do ruído de fundo; c) estímulo à ingestão frequente de água potável fornecida gratuitamente aos operadores"8.

Em relação à medida ressaltada no item “a”, embora sejam necessárias pausas para se evitar sobrecarga vocal não há, ainda, uma quantificação clara na literatura científica sobre a duração de tais micropausas.

Sobre a medida apontada no item "b”, o ruído constitui-se como um dos principais fatores associados ao DVRT ${ }^{9}, 32$. Na NR-178, está estabelecido o nível de até $50 \mathrm{~dB}(\mathrm{~A})$, baseado na Norma Brasileira (NBR) 10152/17 $7^{33}$ como limite aceitável de ruído. Na versão de 1987 da referida NBR, não havia a definição desses níveis para centrais de teleatendimento, considerando-se o valor de salas de computadores como referência, com a variação entre $45 \mathrm{~dB}-65 \mathrm{~dB}$. O primeiro valor indica conforto acústico e o segundo indica o limite aceitável ${ }^{33}$. De acordo com a NBR $10152 / 17^{33}$, o valor médio aceitável em sala de aula seria de 35 dB. Vale salientar, porém, que, quando se refere à saúde vocal, deve-se atentar à relação sinal-ruído (RSR), expressa pela diferença entre o ruído de fundo e a intensidade da emissão realizada pelo falante, necessária para se garantir a inteligibilidade de fala $^{34}$. A relação entre a intensidade da voz do profissional e o nível de ruído de fundo deve ser de $10 \mathrm{~dB}^{35}$. Deste modo, levando-se em conta o nível de $50 \mathrm{~dB}$ estabelecido, o teleoperador teria que falar numa intensidade de, pelo menos, $60 \mathrm{~dB}$ para sobrepor o ruído de fundo. Em ambientes escolares com níveis de ruído ideais, nos quais a RSR mínima deve ser de $15 \mathrm{~dB}^{34}$, a intensidade da emissão seria de $50 \mathrm{~dB}$. Contudo, de acordo com estudo realizado em 2006 em ambiente escolar de ensino fundamental na cidade de Piracicaba (SP), mensurando-se os níveis de ruído, constatou-se valores entre $55 \mathrm{~dB}$ a $102 \mathrm{~dB}^{36}$, em que o professor necessitaria do valor mínimo de $70 \mathrm{~dB}$ de intensidade vocal para sobrepor ao ruído ambiental, gerando uma sobrecarga vocal. A sobrecarga vocal é resultado do uso da voz de forma prolongada, somado a outros fatores como: acústica, qualidade do ar e ruído de fundo, possibilitando atingir o volume e tipo da fonação, ciclos vibratórios das pregas vocais, frequência fundamental, bem como o estado geral da laringe ${ }^{35}$. Maiores níveis de pressão sonora, durante a fonação, implicam numa maior sobrecarga vocal, associada a um aumento do esforço vocal ${ }^{35}$.

Em 2006, foi realizado um estudo de avaliação da exposição de teleoperadores a ruído em Santa Catarina $^{37}$. Os resultados apontaram que os valores médios de exposição a ruído se encontravam entre 66 $\mathrm{dB}$ a $90 \mathrm{~dB}^{37}$, tornando-se valores elevados quando comparados aos parâmetros da nova edição da NBR 10152/17 ${ }^{33}$ Nesta norma, verifica-se a especificação para centrais de telefonia (call center) em valores médios de $50 \mathrm{~dB}^{33}$. Nessa situação, garantir-se-iam melhores condições de produção vocal com menos esforço e exposição à alteração de voz, uma vez que o nível de pressão sonora final chegaria a $60 \mathrm{~dB}$, consistindo em uma menor exposição a sobrecarga vocal ${ }^{35}$.

Por fim, quanto à medida apresentada no item "c", em ambientes com a umidade do ar reduzida, no caso de salas com uso prolongado do ar condicionado, é indicada a ingestão de água em quantidade superior a 2-3 litros ao dia, pois um ambiente seco leva ao ressecamento do trato vocal, gerando uma produção de voz com maior tensão e esforço ${ }^{20}$.

As altas demandas de produtividade em call centers culminam em um ritmo de trabalho acelerado; consequentemente, os teleoperadores, com frequência, não realizam a hidratação suficiente por causa da dificuldade em sair do seu posto de trabalho para realizar pausas fisiológicas entre as ligações. São permitidas apenas 
pausas de dez minutos, insuficientes para atender às necessidades do trabalhador ${ }^{38}$. Desse modo, existe uma limitação para a realização da hidratação ideal no ambiente de trabalho, acarretando o ressecamento do trato vocal e, consequente, sobrecarga das pregas vocais pela impossibilidade da sua livre movimentação.

Situações como as descritas são decorrentes da forma como o ambiente e a organização do trabalho se estruturam de modo a incentivar a competitividade, submetendo o teleoperador a regras rígidas, ao cumprimento de metas de produtividade, à aceleração/otimização do tempo para realização das atividades e à padronização da qualidade vocal exigida pelas empresas ${ }^{38}$.

Alguns autores ${ }^{2,31}$ reiteram o fato de que os teleoperadores recebem uma maior atenção legal em comparação a outros profissionais da voz. Em outras palavras, possuem privilégios normativos, pois os aspectos de saúde e segurança relacionados a sua profissão são dispostos em norma regulamentadora. Ainda assim, é relevante salientar que os fatores de risco inerentes ao trabalho continuam provocando o adoecimento conforme referido anteriormente. Se algo ocorre fora da regra, os trabalhadores são prontamente substituídos, como exemplo, em situações nas quais os distúrbios de voz descaracterizam a qualidade vocal exigida pela empresa ${ }^{38}$.

\section{Nexo Causal}

O reconhecimento do nexo causal entre agravo da voz e trabalho é essencial para que o trabalhador receba benefícios previdenciários de espécie acidentária ou compensações trabalhistas. Houvesse norma autorizando a presunção do nexo entre agravo vocal e trabalho, ou seja, estabelecendo a existência de DVRT ${ }^{2,39,40}$, não seria necessária a comprovação empírica desse nexo em cada caso concreto $^{29,41}$. Nos casos presentes neste estudo, o Judiciário aceitou diversas formas e critérios para a prova do nexo, utilizando os laudos periciais, quando presentes, como norteadores das decisões, sendo examinados e posteriormente aceitos ou não de acordo com a reunião e a análise de todas as demais provas judiciais.

No âmbito previdenciário, o estabelecimento do nexo causal entre o agravo e o trabalho é determinado por técnica específica. A epidemiologia auxilia na relação causal em agravos de elevada prevalência entre os trabalhadores que desempenham certas atividades em empresas dedicadas a ramos específicos ${ }^{42}$. Assim, para além dos casos individuais, é permitida uma presunção jurídica fundada em fatos estatisticamente comprovados. Quando o nexo técnico epidemiológico previdenciário NTEP foi estabelecido, apontou-se para uma relação entre o agravo e o trabalho desempenhado pelo trabalhador, concedido com base no cruzamento de informações entre o CID-10 e a CNAE ${ }^{43}$. Para que o nexo seja presumido, é necessário que essa relação conste na lista em anexo ao decreto. Isto significa que, se o DVRT estivesse na lista e relacionado com as atividades desenvolvidas pelo empregado, não seria necessária a prova minuciosa da culpa do empregador. Neste caso, o ônus de provar a ausência do nexo seria da empresa, conforme o Decreto 3.048/99, art. 337, § $7^{\text {o3 }}$ e a Instrução Normativa INSS/Pres $n^{0} 31 / 08^{44}$. Quando os fatores de risco de ordem ocupacional e agentes causais não estão dispostos no decreto, são encontrados na segunda parte da lista de dupla entrada, ou seja, por agente ou por doença ${ }^{15}$. O estabelecimento do NTEP poderia esclarecer a presunção de que a doença é ocupacional e que esse adoecimento é equivalente a acidente de trabalho ${ }^{45}$. A dúvida sobre essa aplicação do NTEP no Judiciário Trabalhista é objeto de uma Ação Direta de Inconstitucionalidade $(3.931 / 2007-D F)^{46}$. Como não existe qualquer presunção, o DVRT precisa ser provado caso a caso; por isso, justifica-se a presença de perícias nos processos que fizeram parte do presente estudo.

\section{Tipos de Ganho}

Dos trabalhadores que entraram com ações na Justiça, a maioria $(73,5 \%)$, obteve algum tipo de ganho de causa parcial $(42,5 \%)$ ou total (31\%). Dos ganhos obtidos, a maior parte foi por danos morais (50,6\%), seguida por benefícios junto à Previdência Social $(31,0 \%)$ e danos materiais $(8,0 \%)$.

A responsabilidade civil deriva de dano à vítima, distinguindo-se o dano material e o dano moral. $\mathrm{O}$ dano material ${ }^{47}$ gera prejuízos emergentes e lucros cessantes, tendo por critério o tempo. Os prejuízos emergentes ${ }^{47}$ são imediatos, aparecendo no momento em que ocorre o dano. Os lucros cessantes $^{47}$ serão percebidos posteriormente, consistindo no quanto a vítima deixará de ganhar no futuro. Assim, ao ocorrer o problema de voz, emerge o prejuízo ao trabalhador. Este pode se tornar rouco ou afônico, já representando prejuízo emergente ao perder a capacidade de se comunicar. Esse prejuízo imediato precisará ser reparado com tratamentos que restituam a sua voz ou o indenizem pela perda decorrente de um DVRT. Os lucros cessantes, por outro lado, ocorrem quando o trabalhador deixa de receber seu salário porque o problema de voz diminui sua capacidade produtiva. No exemplo do DVRT, tal distinção parece menos evidente porque a perda da voz não tem um preço padrão de mercado estabelecido. Mostra-se mais fácil pensar nas indenizações advindas de um acidente automobilístico em que a vítima é um taxista, por exemplo. Os 
prejuízos emergentes são sanados com o conserto do bem e a indenização de seu valor, permitindo que o motorista reponha o seu patrimônio com um veículo equivalente. Os lucros cessantes se convertem na indenização do valor perdido pelo profissional durante o período em que, pela ausência do automóvel, deixou de trabalhar e de receber o pagamento pelas corridas não realizadas. A perda do bem material é distinta da perda dos lucros que o profissional ficou impedido de auferir. O culpado pela destruição do automóvel é devedor das duas indenizações. Portanto, o empregador deverá indenizar o trabalhador pelos prejuízos vocais decorrentes das suas ações ou omissões no ambiente e organização do trabalho. Além disso, o empregador terá o dever de indenizar o trabalhador pelo valor em dinheiro que ele deixará de ganhar em decorrência do DVRT.

A definição de dano moral vem sendo objeto de intensa disputa na literatura jurídica. Aqui são explicitados dois conceitos bastante distintos: o de dano moral subjetivo (psicológico) e o de dano moral objetivo (social). O dano moral subjetivo ${ }^{47}$ é a dor psíquica causada à vítima pela conduta do empregador. No caso do DVRT, um exemplo de fundamento para a indenização pelo dano moral subjetivo seria a dor da vítima impedida de se comunicar e, portanto, de fielmente expressar seus sentimentos, pensamentos, emoções e outros estados de espírito. $\mathrm{O}$ dano moral objetivo ${ }^{48}$ não se percebe na vítima e sim na imoralidade da conduta causadora do dano. A imoralidade se constata, objetivamente, na conduta do empregador que (des)organiza o ambiente de trabalho de maneira indiferente às necessidades do trabalhador, quer o faça ostensivamente, para a finalidade de lucro, quer o faça ou deixe de fazer, sutilmente, por economia ou por simplesmente não ter qualquer cuidado com a dignidade alheia. A condenação por danos morais objetivos pune a indiferença, o desmazelo, a negligência, o desleixo e o tratamento desumano. Também, estabelece que o empregador deverá indenizar a vítima pelo tratamento indigno a ela dispensado.

Nessa perspectiva, havendo um dano moral ou material, o profissional tem o direito ao ressarcimento financeiro, pois o Direito Trabalhista visa garantir que o trabalhador seja respeitado e preservado ${ }^{49}$.

Ressalta-se que, quando um trabalhador recorre à Justiça, há repercussões econômicas neste fato. São despendidos valores com perícia técnica e pagamento de salários de todo o Poder Judiciário. Segundo o Conselho Nacional de Justiça, os valores direcionados aos recursos humanos da Justiça do Trabalho são responsáveis pela maioria $(91,9 \%)$ das suas despesas. Observa-se que, no ano de 2015, houve um aumento significativo destes gastos para 16,5 bilhões de reais ${ }^{50}$. Em 2020 o total foi de 20,5 bilhões de reais ${ }^{51}$, um aumento de $24,19 \%$ enquanto a inflação do período foi de $25,64 \%{ }^{52}$-, apesar da queda de 2.000 para 1.300 processos por cem mil habitantes no período ${ }^{50,51}$.

Neste estudo, os trabalhadores que obtiveram benefício da Previdência Social foram a maioria (31\%), mesmo não existindo nexo causal formalmente estabelecido. O artigo 20 da Lei $\mathrm{n}^{\circ} 8.213 / 1991^{1}$ discorre sobre duas situações nas quais podem ocorrer acidentes de trabalho. Essas situações são classificadas como doença profissional ("produzida ou desencadeada pelo exercício do trabalho peculiar a determinada atividade") ou doença do trabalho ("adquirida ou desencadeada em função de condições especiais em que o trabalho é realizado e com ele se relacione diretamente"). Em ambas as situações, os agravos deveriam estar nas listas elaboradas pela Previdência Social e pelo Ministério do Trabalho. Embora o DVRT não esteja contemplado nessa lista, o $\S 2^{\circ}$ traz a possibilidade de novas situações ocorrerem como "caso excepcional", podendo também ser considerado como acidente de trabalho.

Por meio do Decreto $\mathrm{n}^{0}$ 6.957/2009 ${ }^{4}$, ainda em vigor, foram definidos agentes patogênicos causadores de doenças profissionais ou do trabalho, associados a agravos definidos pelo CID-10 e atividade econômica classificada pelo CNAE, com vistas a benefícios compensatórios. Neste Decreto, não há relação estabelecida para um DVRT, considerando o trabalho realizado, a doença e os fatores de exposição. Registra-se, contudo, no revogado Decreto ${ }^{0}$ $2.172 / 1997^{5}$, que havia uma menção ao agravo "perturbação da palavra", a ser comprovada por métodos clínicos e objetivos sem estabelecer relação com CNAE, fatores de risco e agravo. Desta maneira, o Judiciário avaliou o nexo de causalidade em cada caso de forma singular por não existirem normas legalmente padronizadas que pudessem ser seguidas em relação ao DVRT, associando fatores de risco presentes no trabalho, agravo (CID-10) e ramo de atividade (CNAE).

O objetivo de compensar os profissionais por danos morais considera a diminuição do sofrimento e da dor individual causada pelo dano ${ }^{49}$. Porém, ao longo do tempo em que as ações na Justiça são desenvolvidas, o efeito poderá ser agravado ainda mais, pelo fato de os trabalhadores, além de adoecidos, também estarem afastados do trabalho, aumentando-se o sofrimento na espera por uma resolução.

Com o reconhecimento formal do DVRT, melhores condições de trabalho seriam garantidas e, em caso 
de adoecimento, o benefício previdenciário poderia ser prontamente concedido diante da realização da perícia técnica da Previdência Social ${ }^{5}$, explicitando diagnóstico de um distúrbio de voz, que apresente relação com a atividade ocupacional desempenhada pelo trabalhador. Os projetos de lei e as normativas existentes teriam mais força para serem cumpridos, reestruturados, ampliados e postos em prática, almejando a redução dos riscos ocupacionais aos quais esses trabalhadores estão, constantemente, expostos. Desse modo, políticas públicas seriam estabelecidas em termos de uma linha de cuidado integral à saúde vocal, contemplando ações de promoção, proteção e recuperação da voz, assim como a vigilância do ambiente de trabalho.

\section{Conclusão}

As ações encontradas na Justiça reconheceram a relação entre distúrbio de voz e trabalho, especialmente em teleoperadores e professores. A reparação do adoecimento causado pelo exercício profissional se efetivou, fundamentalmente, na qualidade de danos morais, com valores bastante variados, demandando longa espera na compensação do agravo. O reconhecimento formal do distúrbio de voz como doença relacionada ao trabalho poderia diminuir o sofrimento vivenciado pelos trabalhadores acometidos, evitar gastos e ações na Justiça. Ademais, auxiliaria no manejo do DVRT, de modo a se criarem políticas públicas, visando melhores condições de trabalho.

\section{Contribuições de autoria}

Os autores contribuíram nas diversas fases da investigação e da redação do artigo, as quais incluíram elaboração do projeto, coleta e análise de dados, redação, revisão e aprovação do texto final para publicação. A autora e os coautores assumem integral responsabilidade pelo trabalho e o conteúdo aqui publicado.

\section{Referências}

1. Brasil. Lei $\mathrm{N}^{\mathrm{o}}$ 8.213, de 24 de Julho de 1991. Dispõe sobre os Planos de Benefícios da Previdência Social e Dá Outras Providências. Diário Oficial da União. 25 jul 1991:14809.

2. Ferracciu CCS, Almeida MS. O distúrbio de voz relacionado ao trabalho do professor e a legislação atual. Rev Cefac. 2014;16(2):628-33.

3. Brasil. Decreto $\mathrm{n}^{\circ}$ 3.048, de 6 de maio de 1999. Aprova o Regulamento da Previdência Social e dá outras providências. Diário Oficial da União. 21 jun 1999:1.

4. Brasil. Decreto $n^{\circ}$ 6.957, de 9 de setembro de 2009. Altera o Regulamento da Previdência Social. Diário Oficial da União. 10 set 2009: 8.

5. Masson MLV, Ferrite S, Pereira LMA, Ferreira LP, Araujo TM. Em Busca do Reconhecimento do Distúrbio de Voz como Doença Relacionada ao Trabalho: Movimento histórico-político. Cien Saude Colet [Internet]. 2017 [acesso em 21 set 2017];24(3):805-16. Disponível em: https:/www.scielo.br/scielo.php?script $=$ sci arttext\&pid $=$ S1413-81232019000300805\&lng $=p t$ $\& n r m=i s o \& t \operatorname{lng}=p t$

6. Brasil. Ministério da Saúde. Secretaria de Vigilância em Saúde. Departamento de Vigilância em Saúde Ambiental e Saúde do Trabalhador. Distúrbio de voz relacionado ao trabalho - DVRT. Brasília, DF: Ministério da Saúde; 2018.

7. Brasil. Ministério do Trabalho. Secretaria de Inspeção do Trabalho. Portaria SIT n ${ }^{\circ}$ 9, de 30 de março de 2007. Aprova o Anexo II - NR17. Diário Oficial da União. 2 abr 2007.
8. Brasil. Ministério do Trabalho e Emprego. Norma Regulamentadora NR-17. Ergonomia [Internet]. 2009 [acesso em 8 ago 2017]. Disponível em: https://sit.trabalho.gov.br/portal/index.php/ctppnrs/nr-17?view $=$ default

9. Martins RH, Pereira ER, Hidalgo CB, Tavares EL. Voice disorders in teachers. A review. J Voice. 2014;28(6):716-24.

10. Rechenberg L, Goulart BNG, Roithmann R. Impacto da atividade laboral de teleatendimento em sintomas e queixas vocais - estudo analítico. J Soc Bras Fonoaudiol. 2011;23(4):301-7.

11. Cavallini M. Telemarketing emprega 1,4 milhão no país; veja como é o trabalho no setor. G1 [Internet]. 6 out 2012. [acesso em 20 ago 2017] Disponível em: http:/g1.globo.com/concursos-e-emprego/ noticia/2012/10/telemarketing-emprega-14-milhaono-pais-veja-como-e-o-trabalho-no-setor.html

12. Micheletti C. Telemarketing cresceu 198\% e ganhou profissionalismo nos últimos seis anos. Empregos.com.br [Internet]. 27 out 2015 [acesso em 12 abril 2018]. Disponível em: https://carreiras. empregos.com.br/seu-emprego/telemarketingcresceu-198-e-ganhou-profissionalismo-nosultimos-seis-anos/

13. Instituto Nacional de Estudos e Pesquisas Educacionais Anísio Teixeira (BR). Sinopse Estatística da Educação Básica 2017 [Internet]. 2018 [acesso em 24 abr 2018]. Disponível em: http://portal.inep.gov.br/sinopses-estatisticas-daeducacao-basica 
14. Brasil. Ministério da Saúde. Portaria no 1339 , de 18 de Novembro de 1999. Lista de Doenças Relacionadas ao Trabalho. Brasília, DF: Ministério da Saúde; 1999.

15. Brasil. Ministério da Saúde. Organização PanAmericana da Saúde. Doenças relacionadas ao trabalho: manual de procedimentos para os serviços de saúde. Brasília, DF: Ministério da Saúde; 2001.

16. Brasil. Ministério da Saúde. Secretaria de Vigilância em Saúde. Departamento de Vigilância em Saúde Ambiental, do Trabalhador e de Emergências em Saúde Pública. Coordenação Geral de Saúde do Trabalhador. Portaria MS/ $\mathrm{GM} \mathrm{n}^{0}$ 2.309, de 28 de agosto de 2020. Altera a Portaria de Consolidação $\mathrm{n}^{0}$ 5/GM/MS, de 28 de setembro de 2017, e atualiza a Lista de Doenças Relacionadas ao Trabalho (LDRT). Diário Oficial da União [Internet]. 1 set 2020 [citado em 10 set 2020]: 40-73. Disponível em https://www.in.gov. br/en/web/dou/-/portaria-n-2.309-de-28-de-agostode-2020-275240601

17. Brasil. Ministério da Saúde. Secretaria de Vigilância em Saúde. Departamento de Vigilância em Saúde Ambiental, do Trabalhador e de Emergências em Saúde Pública. Coordenação Geral de Saúde do Trabalhador. Portaria MS/GM $\mathrm{n}^{\circ} 2.345$, de 02 de setembro de 2020. Torna sem efeito a Portaria $\mathrm{n}^{\circ}$ 2.309/GM/MS, de 28 de agosto de 2020. Diário Oficial da União [Internet]. 2 set 2020 [citado em 2 set 2020]. Disponível em: https:// www.in.gov.br/en/web/dou/-/portaria-n-2.345-de-2de-setembro-de-2020-275488423

18. Silva P. Vocabulário Jurídico. 15a ed. Rio de Janeiro: Forense;1998.

19. Pesquisa de Jurisprudência [Internet]. Brasília, DF: Tribunal Superior do Trabalho (BR). [2016?] - [acesso em 3 de set de 2020]. Disponível em: https://jurisprudencia.tst.jus.br/

20. Behlau M organizador. Voz: o livro do especialista. Rio de Janeiro: Revinter; 2001.

21. Caporossi C, Ferreira LP. Sintomas vocais e fatores relativos ao estilo de vida em professores. Rev Cefac. 2011;13(1):132- 9.

22. Przysiezny PE, Przysiezny LTS. Work-related voice disorder. Braz J Otorhinolaryngol [Internet]. 2015 [acesso 20 ago 2016];81(2): 202-11. Disponível em: https://doi.org/10.1016/j.bjorl.2014.03.003

23. Costa O, Pontes P, Almeida S. Distúrbio de voz relacionado ao trabalho. In: Mendes R editor. Patologia do trabalho. São Paulo: Atheneu; 2013. p. 1167-76.

24. Almeida SIC, Pontes P. Síndrome Disfônica Ocupacional: Novos Aspectos desta Entidade Nosológica. Arq Int Otorrinolaringol. 2010;14(3):346-50.

25. Rio de Janeiro. Secretaria Estadual de Saúde do Rio de Janeiro (SES/RJ). Resolução SES/RJ no. 674/2013. Redefine a relação de doenças e agravos de notificação compulsória no âmbito do Estado do Rio de Janeiro. Diário Oficial do Estado [Internet]. 16 jul 2013 [acesso em 20 ago 2017]. Disponível em: http://www.rio. rj.gov.br/dlstatic/10112/4364979/4115670/ ResolucaoSESN674DE12.07.2013.pdf

26. Associação Brasileira de Otorrinolaringologia e Cirurgia Cérvico-Facial; Academia Brasileira de Laringologia e Voz; Associação Nacional de Medicina do Trabalho (BR); Conselho Regional de Medicina do Estado do Rio de Janeiro; Sociedade Médica do Estado do Rio de Janeiro; Sociedade de Otorrinolaringologia do Estado do Rio de Janeiro, et al. Relatório final: Carta do Rio e seus anexos: submetidos e definidos pela Plenária do Consenso 2004. Consenso Nacional sobre Voz Profissional: Voz e trabalho uma questão de saúde e direito do trabalhador; 13 14 agosto 2004; Centro de Convenções do Hotel Glória; Rio de Janeiro. São Paulo: Academia Brasileira de Laringologia e Voz; 2004.

27. Behlau M, Madazio G, Oliveira G. Functional dysphonia: strategies to improve patient outcomes. Patient Relat Outcome Meas. 2015;6:243-53.

28. Behlau, M, Zambon F, Guerrieri AC, Roy N. Epidemiology of voice disorders in teachers and nonteachers in Brazil: prevalence and adverse effects. J Voice. 2012;26(5):665.e9-665.e6.65E18.

29. Giannini SPP, Latorre MRDO, Ferreira LP. Distúrbio de voz relacionado ao trabalho docente: um estudo caso-controle. CoDAS. 2013;25(6):566-76.

30. Ferreira LP, Servilha EAM, Masson MLV, MRMF Baldini Maciel. Políticas públicas e voz do professor: caracterização das leis brasileiras. Rev Soc Bras Fonoaudiol. 2009;14(1):1-7.

31. Servilha EAM, Leal ROF, Hidaka MTU. Riscos ocupacionais na legislação trabalhista brasileira: destaque para aqueles relativos à saúde e à voz do professor. Rev Soc Bras Fonoaudiol. 2010;15(4):505-13.

32. Cantor Cutiva LC, Vogel I, Burdorf A. Voice disorders in teachers and their associations with work - related factors: a systematic review. J. Commun Disord. 2013;46(2):143 -55.

33. Associação Brasileira de Normas Técnicas. Norma Técnica. NBR 10152:2017. Acústica - Níveis de pressão sonora em ambientes internos e edificações. Rio de Janeiro: Associação Brasileira de Normas Técnicas; 2017.

34. Švec JG, Granqvist S. Tutorial and Guidelines on Measurement of Sound Pressure Level in Voice and Speech. J Speech Lang Hear Res. 2018;61(3):441-61.

35. Vilkman E. Occupational safety and health aspects of voice and speech professions. Folia Phoniatr Logop. 2004 Jul-Aug;56(4):220-53.

36. Libardí A. O ruído em sala de aula e a percepção dos professores de uma escola de ensino fundamental de Piracicaba. Disturbios comun. 2006;18(2):167-78. 
37. Vergara EF, Steffani J, Gerges SNY, Pedroso M. Avaliação da exposição de operadores de teleatendimento a ruído. Rev Bras Saude Ocup [Internet]. 2006 [acesso em $25 \mathrm{abr}$ 2019];31(114):161-72. Disponível em: http://dx.doi. org/10.1590/S0303-76572006000200014

38. Guena RM. Dando voz ao trabalhador: os significados da disfonia para os operadores de telemarketing [dissertação]. Salvador: Universidade Federal da Bahia; 2009.

39. Fabron EM, Nemr NK, Giannini SP. Seminários de Voz da PUC-SP: análise da trajetória entre os anos de 1993 a 2009. Disturbios comun [Internet]. 2010;22(3):241-9. [acesso em 21 abril 2018]. Disponível em: https://repositorio. unesp.br/bitstream/handle/11449/115106/ ISSN21762724-2011-22-03-241-249. pdf?sequence $=1 \&$ is Allowed $=\mathrm{y}$

40. Ferreira LP, Bernardi APA. Distúrbio de voz relacionado ao trabalho: resgate histórico. Disturbios comun [Internet]. 2011 [acesso em 20 ago 2016];23(2):233-6. Disponível em: https:// revistas.pucsp.br/index.php/dic/article/view/8285

41. Ortiz E, Costa EA, Spina AL, Crespo NA. Proposta de modelo de atendimento multidisciplinar para disfonias relacionadas ao trabalho: estudo preliminar. Rev Bras Otorrinolaringol. 2004;70(5):590-6.

42. Silva E Jr. Nexo Técnico Epidemiológico e sua aplicação perante a Justiça do Trabalho nas ações de indenização por acidentes do trabalho e doenças ocupacionais. Rev Tribut Reg Trab 15 Reg. 2012(40):129-138.

43. Brasil. Instituto Nacional de Seguro Social. Nexo Técnico Epidemiológico Previdenciário. 2019. [acesso em 10 set 2020]: Disponível em: https://www.inss.gov.br/orientacoes/nexos-tecnicosprevidenciarios/

44. Brasil. Instituto Nacional de Seguro Social. Instrução Normativa INSS/PRESn ${ }^{\circ}$ 31, de 10 de setembro de 2008. Dispõe sobre procedimentos e rotinas referentes ao Nexo Técnico Previdenciário, e dá outras providências. Diário Oficial da União. 11 set 2008.

45. Dallegrave Neto JA. A Indenização do dano acidentário na justiça do trabalho. Rev Trib Reg Trab 1 Reg. 2010;21(49):115-32.

46. Brasil. Supremo Tribunal Federal. Ação Direta de Inconstitucionalidade 3.931 Distrito Federal [Internet]. 2007 [acesso em 7 maio 2019]. Disponível em: http://portal.stf.jus.br/processos/ downloadPeca.asp?id=306936587\&ext $=$.pdf

47. Bittar CA. Reparação civil por danos morais. São Paulo: Saraiva; 2015

48. Andrade AGC. Dano moral e indenização punitiva. Rio de Janeiro: Forense; 2006.

49. Machado LC. O dano moral na relação de trabalho: uma abordagem jurisprudencial. Ambito Jurid [Internet]. 2011 [acesso em 14 set 2020];(87). Disponível em: https://ambitojuridico.com.br/ edicoes/revista-87/o-dano-moral-na-relacao-detrabalho-uma-abordagem-jurisprudencial/

50. Conselho Nacional de Justiça (BR). Justiça em números 2016. Ano-base 2015. Brasília, DF: Conselho Nacional de Justiça; 2016.

51. Conselho Nacional de Justiça (BR). Justiça em números 2020. Ano-base 2019 Brasília, DF: Conselho Nacional de Justiça; 2020 [acesso em 28 ago 2020]. Disponível em: https://www.cnj. jus.br/wp-content/uploads/2020/08/WEB-V3Justi\%C3\%A7a-em-N\%C3\%BAmeros-2020atualizado-em-25-08-2020.pdf

52. Instituto Brasileiro de Geografia e Estatísticas. Índice Nacional de Preços ao Consumidor Amplo IPCA. Brasília, DF: Instituto Brasileiro de Geografia e Estatísticas; 2020 [acesso em 28 ago 2020]. Disponível em: https:/www.ibge.gov.br/estatisticas/ economicas/precos-e-custos/9256-indice-nacionalde-precos-ao-consumidor-amplo.html? =\&t=serieshistoricas 